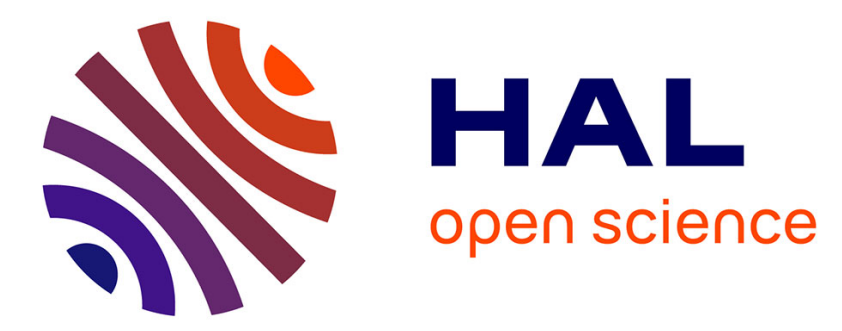

\title{
The out-of-the-loop Brain: A neuroergonomic approach of the human automation interaction
}

Bruno Berberian, Bertille Somon, Aïsha Sahaï, Jonas Gouraud

\section{To cite this version:}

Bruno Berberian, Bertille Somon, Aïsha Sahaï, Jonas Gouraud. The out-of-the-loop Brain: A neuroergonomic approach of the human automation interaction. Annual Reviews in Control, 2017, 44, pp.303-315. 10.1016/j.arcontrol.2017.09.010 . hal-01729199

\section{HAL Id: hal-01729199 \\ https://hal.science/hal-01729199}

Submitted on 12 Mar 2018

HAL is a multi-disciplinary open access archive for the deposit and dissemination of scientific research documents, whether they are published or not. The documents may come from teaching and research institutions in France or abroad, or from public or private research centers.
L'archive ouverte pluridisciplinaire HAL, est destinée au dépôt et à la diffusion de documents scientifiques de niveau recherche, publiés ou non, émanant des établissements d'enseignement et de recherche français ou étrangers, des laboratoires publics ou privés. 


\section{The Out-Of-The-Loop Brain: A neuroergonomic approach of the human automation interaction}

\author{
Bruno Berberian, Bertille Somon, Aïsha Sahaï, \\ Jonas Gouraud \\ Information Processing and Systems \\ Department, \\ ONERA, Salon de Provence, France \\ bruno.berberian@onera.fr
}

\begin{abstract}
:
The world surrounding us has become increasingly technological. Nowadays, the influence of automation is perceived in each aspect of everyday life. If automation makes some aspects of life easier, faster and safer, empirical data also suggests that it could have negative performance and safety consequences regarding human operators, a set of difficulties called the "out-of-the-loop" (OOTL) performance problem. However, after decades of research, this phenomenon remains difficult to grasp and counter. In this paper, we propose a neuroergonomics approach to treat this phenomenon. We first describe how automation impacts human operators. Then, we present the current knowledge relative to this OOTL phenomenon. Finally, we describe how recent insights in neurosciences can help characterize, quantify and compensate this phenomenon.
\end{abstract}

Keywords: OOTL phenomenon, Automation, Vigilance, Neuroergonomics

Acknowledgement: This work was supported by an ANR grant (Young researcher program - ANR-15-CE26-0010-01); and the 'Direction Générale de l'Armement' (DGA).

\section{The problem with automation}

Progress in automation technology has profoundly changed our modern society. Almost all aspects of our lives are impacted while even more radical changes are expected in the future with increasing computer performances. The way such developments will shape the future is not entirely clear, but the inexorable drive toward even more automation will continue.

What is clear at the moment is that automation makes some aspects of life safer, easier and faster. It leads to superior productivity and efficiency. Wiener and Curry (1980) depicted the image of automation as follows:
"Quiet, unerring, efficient, totally dependable machines, the servant of man, eliminating all human error, and offering a safe and cost-effective alternative to human frailty and caprice. The traditional dream of traditional engineers has been to solve the problem of human error by eliminating its source."

This fascination regarding the possibilities afforded by technology often obscures the fact that automation has profoundly changed the nature of human work. Understanding the characteristics and the dynamics of this transformation is vital for successful design of new automated systems.

\section{From manual control to supervisory control}

Adding "automation" has been considered for a long time as a simple substitution of human activity for machine activity (substitution myth, see Woods \& Tinapple, 1999). Unfortunately, such assumption corresponds to a vague and bleak reflection of the real impact of automation: automation technology transforms human practice and forces people to adapt their skills and routines (Dekker \& Woods, 2002). Particularly, whereas the human operator was initially involved in manual control functions including process planning, decision making, selecting responses and implementing strategies, he is now relegated to the role of passive information processor. He has to monitor the actions of the system, to understand these actions, to watch for deviations and failures, and to take over when necessary (Moray, 1986; Sheridan \& Verplank, 1978). There is no denying that such transformation underlines a certain irony since designers who try to eliminate the operator still leave the operator to do the tasks designers cannot automate (see Bainbridge, 1983). Moreover, as pointed out by Flemisch and colleagues (2012), in addition to control, authority, ability and responsibility are also modified according to the level of automation within the human-machine system.

This new form of interaction between humans and machines produced new loads and difficulties for the humans responsible for the operating systems. Especially, empirical data suggest that these changes have many negative performance and safety consequences associated with it stemming from the human 
out-of-the-loop (OOTL) performance problem (e.g. Billings, 1991; Endsley \& Kiris, 1995; Kaber \& Endsley, 1997; Sarter \& Woods, 1995; C. Wickens, 1992; Wiener \& Curry, 1980). For decades, this OOTL performance problem has appeared as a critical issue for system designers. In this article, we aim at reviewing the current knowledge about this phenomenon, the limits of the current approach and the potential benefits to integrate recent insights in neuroscience to progress in its comprehension.

\section{OOTL: a well-known phenomenon?}

The OOTL phenomenon corresponds to a deterioration of the operator's performance when interacting with highly automated system. The terms "total confusion" (Bureau d'Enquête et d'Analyse, 2002, p167; National Transport Safety Board, 1975, p17), "surprise effect" (Bureau d'Enquête et d'Analyse, 2012a, p10, 2016, p44) or "no awareness of the current mode of the system" (Bureau d'Enquête et d'Analyse, 2012b, p178) indicate a similar process - a mental state in which the operator has lost his or her situation awareness and is not able to monitor the system efficiently. At an operational level, the OOTL performance problem induces a performance decrease whenever trying to transfer manual control over the system. Amongst other problems, an operator who is OOTL might take longer or be completely unable to detect an automation failure, decide if an intervention is needed, and find the most adequate action. In the current context of the continued increase in automation, understanding the sources of human-system interaction difficulties is crucial.

\subsection{Becoming Out-Of-The-Loop}

The control theoretical perspective is a useful concept when considering human-machine systems, particularly for understanding when and how control can be lost, which is highly undesirable in safety critical systems. The concept of control can be seen as a control loop in the light of Neisser's perceptual cycle (Neisser, 1976). As human beings we perceive through our senses, analyze and make decisions via cognitive functions and act using our limbs. Importantly, humans act upon feedback from previous events and perceptions and are thereby always part of several control loops simultaneously. More precisely, in the language of control theory, a system has a desired state, means for adjusting the system toward that desired state, and then, a feedback loop, in which the actual state of the system is compared with the desired state, so that additional correction can be performed if there is a mismatch. The combination of this control plus feedback is called the control loop, and when a human is manually operating the equipment, the human is an essential element of the control loop hence the saying: "the person is in the loop". On the other hand, when a high level of automation is implemented, the automation takes care of the lower level actions and the human operators simply watches over the system, presumably ever-alert for deviations and problems. In other words, operators are relegated to passive information processors: they are "out of the loop".

To summarize, the OOTL phenomenon corresponds to a lack of control loop involvement of the human operator. Automation technology has created an increasing distance between the human operator and the loop of control, disconnecting him from the automation system. Such a removal leads to a decreased ability from the human operator to intervene in system control loops and assume manual control when needed in overseeing automated systems (see following sections).

Interestingly, automation has been shown to impact operators' information acquisition, information analysis, decision making, and action (Parasuraman \& Wickens, 2008). Thus, a major issue in implementing automation relies on its impact on operator situation awareness (SA). During the last decades, a large body of research has been dedicated to this issue. The following section aims at reviewing briefly the main results obtained.

\subsection{Situation awareness and OOTL}

Situation awareness (SA) can be thought of as an internalized mental model of the current state of the operator's environment (Endsley, 2016). Interestingly, the loss of situation awareness underlies a great deal of the out-ofthe-loop performance problem (for a recent review, see Endsley, 2017; Parasuraman \& Wickens, 2008). Particularly, OOTL phenomenon is characterized by both a failure to detect and to understand the problem, and by difficulties to find appropriate solutions.

Several works indicate a lack of operator awareness of automation failures and a decrease in detection of critical system state changes when involved in automation 
supervision (Endsley \& Kiris, 1995; Metzger \& Parasuraman, 2001; Parasuraman \& Riley, 1997; C. Wickens, 1992). As an illustration, Galsterand colleagues (2001) found that passive monitoring with airborne control of aircraft separation, which would be the case under mature Free Flight, led to a marked decrease in conflict detection performance by Air Traffic Control officers (ATCos) under high traffic load. At the same time, when acting as monitors of an automated system, operators are usually slow in detecting system failure (Endsley, 1996). For example, Willems and Truitt (1999) found that under passive monitoring, response times to questions probing traffic awareness became longer, and recall of data blocks poorer with increasing traffic load.

In addition to the degradation in detecting an issue occurred and needs an intervention, operators may encounter difficulties to develop sufficient understanding of the situation in order to overcome the problem (for a metaanalysis, see Onnasch, Wickens, Li, \& Manzey, 2014). For example, Wickens and Kessel $(1979,1981)$ highlighted longer system recovery times and poor response accuracy for operators who had been removed from control loops before critical events requiring intervention. This delay may avoid operators to carry out all the tasks they are required to perform or lower the effectiveness of actions taken. Furthermore, during failure modes, operators who have been removed from the system control may not know what corrective actions are needed to stabilize the system and bring them back to control. Various examples of incidents and accidents resulting from these system misunderstandings have been reported in the literature (Billings, 1997; Funk et al., 1999; Sarter \& Woods, 1995).

"Automation surprises" are a direct instantiation of these difficulties in automation understanding and take-over situations (Sarter, Woods, \& Billings, 1997). Automation surprise is said to occur when the automation behaves in a manner different from what the operator expects (Palmer, 1999). When interacting with automated systems, human operators will develop a mental model of the system's behavior and use it to anticipate how the machine will behave in the near future. However, with the increase of the system complexity (for example, the multiplication of the number of "modes"), it is sometimes difficult for the human operator to track the evolution of their automated partners. This can result in situations where the operator is surprised by the behavior of the automation, and as consequence, he asks questions such as: "what is it doing now?", "why did it do that?" or "what is it going to do next?" (Wiener, 1989). These "automation surprises" are particularly well documented (e.g. Degani \& Heymann, 2000; Palmer, 1995; Sarter \& Woods, 1994, 1995) and have been listed as one of the major causes of incidents on the civilian aviation (see for example FAA, 1995).

These previous studies indicate a lower level of situation awareness when people operate as monitors of automated systems (for a recent illustration, see Dao et al., 2009). Several factors - vigilance decrement, complacency, system opacity - could contribute in this degradation. In the following section, we will introduce these different factors summarizing the main points for each one.

\subsection{Factors impacting SA in the context of automation}

\subsubsection{Vigilance decrement}

As previously explained, automation technology has profoundly changed the human role. This new role leads to an increasing demand for the pilot to monitor systems for possible failures. Consequently, vigilance has become a crucial component of human performance in many work environments where automated systems are common.

Vigilance, or sustained attention, denotes the ability to sustain attention to a task for a period of time in order to detect and respond to infrequent critical events (Davies \& Parasuraman, 1982; Warm, Parasuraman, \& Matthews, 2008). A typical finding in human factors is the existence of a decrease of human operator vigilance in case of interaction with highly automated system (see for example O'Hanlon, 1981; Wiener, 1988; Strauch, 2002).

Several factors could explain such difficulties. One unintended consequence of automation for human operators is boredom. Indeed, highly automated environments require maintaining high levels of vigilance during a long period of time. In many cases, operators' processes are reduced to monitoring activities, waiting for the unlikely system anomaly. Resulting boredom increases the likelihood of operators' distraction, which ultimately can affect system performance if operators miss or respond late to critical events. Numerous studies have confirmed that, at least during some phases of 
the flight, automation can indeed lower pilots workload and free up time (Casner, 2009; Roscoe, 1992; Wiener, 1989).

Moreover, several studies show that sustained attention over hours cannot be achieved (e.g., Davies \& Parasuraman, 1982, Matthews \& Davies, 2001; Methot \& Huitema, 1998). Research on vigilance suggests that time on task decreases significantly the ability to discriminate infrequent and unpredictable signals from a noisy background of no signals (Mackworth, 1948; Parasuraman, 1979; Teichner, 1974; Warm, 1984). For example, Thackray and Touchstone (1989) showed an increase in detection times of about $50 \%$ after one hour on task when students had to detect conflicts manually in a simplified version of an air traffic control task.

This vigilance decrement has been largely discussed and several theories have been proposed (for a furnished discussion, see Warm, Parasuraman, \& Matthews, 2008). Both change in vigilance level and deterioration of attentional mechanisms could cause a degradation of the monitoring process involved in supervisory tasks. This would eventually lead to decrease performance in failure detection and system understanding.

\subsubsection{Complacency}

Together with this difficulty to maintain high levels of vigilance in time, decrease in vigilance could result from an overreliance on automation, the so-called "complacency phenomenon" (see Parasuraman, Molloy, \& Singh, 1993). Complacency defines the cognitive orientation towards highly reliable automation, especially prior to the first time it has failed in the user's experience. Particularly, complacency is created as operators maintain beliefs that the technical system is more competent than it actually is (Lee, 2006). This overreliance on automation represents an important aspect of misuse that can result from several forms of human error, including decision biases and failures of monitoring (Wiener, 1988; Parasuraman, Molloy, \& Singh, 1993; Parasuraman \& Riley, 1997; Singh, Molloy, \& Parasuraman, 1993). In particular, it has been showed that high levels of trust in automation which is not perfectly reliable lead to overreliance and failure to monitor "raw" information sources providing input to automation (see Parasuraman, Molloy, \& Singh, 1993; Moray \& Inagaki, 2000; Bailey \& Scerbo, 2007; Bagheri \& Jamieson, 2004; Metzger \& Parasuraman, 2005; Wickens,
Dixon, Goh, \& Hammer, 2005; Lorenz, Di Nocera, Roettger, \& Parasuraman, 2002; Manzey, Bahner, \& Hueper, 2006). In extreme cases, the operator no longer actively processes information to maintain an awareness of the system state, diminishing his or her ability to recover from automation failure. Interestingly, these findings have been modeled computationally (Farrell \& Lewandowsky, 2000; Wickens \& Dixon, 2007).

\subsubsection{System Opacity}

A third factor related to automation could impact operator's SA, namely the system opacity. Whatever the merits of any automation technology, adding or expanding the machine's role changes the cooperative architecture, in turn changing the human's role often in profound ways (Sarter, Woods, \& Billings, 1997). Creating partially autonomous machine agents is, in part, like adding a new team member. One aftermath is the introduction of new coordination demands and the emergence of new classes of issues due to failures in the human-machine relationship.

Particularly, the role of passive information processor involves observing the actions of other operators or computer controllers and agreeing or disagreeing with them. In this condition, understanding the actions of the automated system is essential for human operator. However, as previously discussed with the concept of "automation surprise", such understanding is difficult to obtain. The lack of system predictability is certainly a central point in understanding OOTL phenomenon and associated takeover difficulties (Norman, 1990; Christoffersen \& Woods, 2000; Dekker \& Woods, 2002; Klein, Woods, Bradshaw, Hoffman, \& Feltovich, 2004). With the progress of the technology, current complex systems tend to develop cascades and runaway chains of automatic reactions that lower, or even eliminate predictability and cause outsized and unpredicted events (Taleb, 2012). This is what we may call "system opacity": the difficulty for a human operator to have a clear idea of the system's intentions and to predict the sequence of events that will occur. In this sense, the main problem with automation is not the automation itself, but rather its inappropriate design within the human-computer interaction (Norman, 1990). For example, previous studies have shown that ATCo performance can be compromised when they do not have readily access to aircraft intent information (Castaño 
\& Parasuraman, 1999; Galster, Duley, Masalonis, \& Parasuraman, 2001).

This issue of cooperation amongst team (and/with automates) has led research on (team) performance and situation awareness investigating how computer might support collaboration between operators. This line of research has provided interesting concepts and methods: shared SA (Endsley, 1995; Salas et al. 1995; Bolstad and Endsley 2000; Nofi 2000), situated SA (Chiappe et al. 2012; Chiappe, Strybel, \& Vu 2012; Durso et al. 1999), distributed cognition framework (Hutchins, 1995; Stanton, 2016), adaptive automation (see Miller \& Parasuraman, 2007). These works have brought different human factors/ ergonomics (HF/E) principles as a solution for better team play. As an illustration, we can mention the work of Dekker \& Woods (2002) who proposed several principles to shape how information about automation and the processes in controls are displayed to the operator to enhance human-automation teaming: highlighting changes, displaying future projections, and visually integrating information (ecological displays, see also Parasuraman et al, 2000). As stated by Bannon (Bannon, 1991), "what was required was a better cognitive Coupling between the human and the new universal machine, the computer, and not simply better designed surface characteristics of displays." Another illustration refers to the function allocation framework (see Gaines, McCarthy, Fallon, \& Bannon, 2000, for a recent review) which aims at thinking about partial automation, i.e. systems in which the delivery of a system function is performed by a combination of human and automated activities. Particularly, several works proposed intermediate levels of automation (LOAs) for maintaining operator involvement in complex systems control and increase situation awareness (see for example Kaber \& Endsley, 2004).

As illustrated in the previous sections, interest of the scientific community towards OOTL phenomenon has grown during the last decades. However, after decades of research, this phenomenon remains difficult to grasp and counter and recent tragic accidents remind us the difficulty for human operators to interact with highly automated systems. Moreover, with the development of autonomous cars, which should come onto our roads in a few years, everyone (not only expert operators) could be concerned by such difficulties. As previously presented, automation technology has the potential to dramatically change the way we interact with our environment. This transformation clearly raises question concerning the place of the human operator with future technological systems. Dealing with these different issues is a necessary step to make future systems safer, more reliable, and more usable.

In this paper, we support the idea that neurosciences can help improve our comprehension of the OOTL performance problem and to develop new methodologies for mitigating its negative impact. We assume that recent progresses in neurosciences can bring new perspectives to think about OOTL phenomenon and bring innovative contributions to characterize, quantify and compensate this critical phenomenon in near future.

\section{Beyond the current approach of the OOTL phenomenon: a neuroergonomics approach}

As previously detailed, cognitive engineering literature has discussed at length the OOTL phenomenon and the implication of different mechanisms in its emergence. SA, vigilance decrement, complacency and human machine misunderstanding are different concepts/constructs used to explain these difficulties in human automation interaction.

Certainly, these different concepts have been useful in understanding human-system performance in complex work environments. In contrast to Dekker and colleagues (Dekker \& Hollnagel, 2004; Dekker \& Woods, 2002), we do not deny the scientific viability of these constructs, nor their diagnostic value in assisting $\mathrm{HF} / \mathrm{E}$ practitioners to formulate specific solutions when any of the three constructs suggests suboptimal human-system interaction (for an interesting discussion, see Parasuraman, Sheridan, \& Wickens, 2008).

However, we agree that these constructs lack a level of detail and thus fail to fully account for a psychological mechanism needed to connect features of the sequence of events to the outcome (Endsley 1999). Billings nicely pointed this deficit 20 years ago:

\footnotetext{
"The most serious shortcoming of the situation awareness construct as we have thought about it to date, however, is that it's too neat, too holistic and too seductive. We heard here that deficient SA was a causal
} 
factor in many airline accidents associated with human error. We must avoid this trap: deficient situation awareness doesn't cause anything. Faulty spatial perception, diverted attention, inability to acquire data in the time available, deficient decisionmaking, perhaps, but not a deficient abstraction!'” (Billings 1996)

Two decades later, these different constructs have been partly linked to information processing or other psychological processes (for SA, see Durso et al., 2007; for trust, see Lee \& Lee, 2004), but it remains that the underlying cognitive mechanisms of the OOTL phenomenon remains largely unknown. The neuroergonomics approach of this phenomenon could introduce new tools and models to think about human-automation interaction.

Neuroergonomics is the study of brain and behavior at work. This interdisciplinary area of research and practice merges the disciplines of neurosciences and ergonomics in order to maximize the benefits of each. Neuroergonomics uses existing and emerging models in neurosciences to design technologies and work environments for safer and more efficient operations. Here, we propose to use the recent insights in neuroscience to understand changes induced by automation. Note that we propose to focus on the cognitive mechanisms involved in monitoring tasks, as the degradation of the monitoring performance appears as the first concern in the OOTL phenomenon.

With this in mind, we will introduce in turn three neuroscientific concepts, namely, the Performance Monitoring function, the Mind Wandering and the Sense of Agency. We will explain how these different concepts are related to the OOTL phenomenon and how they open new perspectives to characterize, monitor and compensate it.

\subsection{The performance monitoring function}

One important behavioural aspect of the OOTL performance problem is reflected in an insufficient monitoring and checking of automated functions, i.e., information on the status of the automated functions is sampled less often than necessary (see for example Kaber \& Endsley, 1997). As an illustration, various works indicate a decreased ability to detect critical system state changes when involved in automation supervision (for a review see Endsley \& Kiris, 1995)..

At the neurocognitive level, performance monitoring (PM) is defined as "[...] a set of cognitive and affective functions determining whether adaptive control is needed and, if so, which type and magnitude is required." (Ullsperger, Danielmeier, \& Jocham, 2014). This cognitive function is used both for monitoring of our own action, but also for the actions of another agent or a system. We assume that the recent insights about the anatomical substrate of this process (see for example Bonini et al., 2014) can help characterize the degradation of the quality of the monitoring involved in OOTL phenomenon.

In particular, evidence from neuroimaging, EEG, and invasive recordings in humans and nonhuman primates converge on the currently widely accepted view that the PM function is implemented by a cortico-subcortical network connected to the posterior medial frontal cortex (pMFC). Since the discovery of the errorrelated negativity (ERN) and the error positivity (Pe; Falkenstein, Hohnsbein, Hoormann, \& Blanke, 1991), several further temporally and topographically defined eventrelated potentials (ERPs) have been linked to performance monitoring at different stages of goal-directed behaviour (i.e., the feedbackrelated negativity or FRN, the prediction error potential or $\mathrm{PE}$, the stimulus preceding negativity or SPN, the lateralized readiness potential or LRP and so on). Each of these signals could be considered as a physiological marker of response-monitoring processes in case of self-monitoring. Nowadays, the myriad of studies in different research fields dedicated to goal-directed behaviour allows to have a wide understanding of this neurophysiological system and its specific components. Self-PM seems to be quite well understood in theory and is applied in several contexts (aviation: Shappell et al., 2007; medicine: Taylor, Stern, \& Gehring, 2007).

More recently, several authors have tried to expand those results to the monitoring of others' performance, i.e. another agent, human or artificial. Indeed, by observing others, we are able to learn from their mistakes (like babies learn by observing their parents) in accordance with the reinforcement-learning theory (RL, Holroyd \& Coles, 2002). Some studies suggest that observation of our own errors (error execution monitoring) and ones of 
others (error observation monitoring) would involve the performance monitoring system in the same way (Carp, Halenar, Quandt, Sklar, \& Compton, 2009; Jääskeläinen et al., 2016; Koban, Pourtois, Vocat, \& Vuilleumier, 2010; Miltner, Brauer, Hecht, \& Trippe, 2004; van Schie, Mars, Coles, \& Bekkering, 2004; Yu \& Zhou, 2006 to cite a few). However, this is still under debate. Moreover, several authors addressed the question of a similarity in the cognitive processes involved in the supervision of human and artificial agents, and some have even found the same type of ERPs (i.e. an observational ERN and Pe - oERN, oPe - and a LRP) and the same neural activation (i.e. in the pMFC) than in self-PM (Padrão, GonzalezFranco, Sanchez-Vives, Slater, \& RodriguezFornells, 2016; Pavone et al., 2016; Ullsperger, Nittono, \& von Cramon, 2007). As an illustration, Padrão and colleagues (2016) studied system failure through the use of virtual reality avatar embodiment. In their study, participants had to perform a task (i.e. goal-directed behaviour), and their virtual reality avatar performed the same movements. However, on several occasions the system was wrong and the avatar performed an erroneous action creating a system failure. Electrophysiological recording showed PM activity at fronto-central locations, similar to self-PM, but delayed. Likewise, Gentsch and colleagues (2009) studied system malfunctions by adding loose contacts on the participants' response button. The brain activity recording showed again PM activity with fronto-central activation and observational PM ERPs.

Our hypothesis is that the OOTL performance problem is linked to the degradation of this PM function characterized by a decrease of the pMFC activity (decrease of the amplitude and /or increase in the latency of the ERPs related to the PM activity). As the OOTL phenomenon leads to a decreased ability to monitor the automated system and detect its errors, deciphering the neural correlates of other's PM and how they can be degraded could permit to understand and maybe counter the OOTL phenomenon (see Somon, Campagne, Delorme, \& Berberian, 2017 for a review on this subject). A few authors have started to raise this concern, and looked at the impact of various factors (mind-wandering: Kam et al., 2012; time on task: Thomson, Seli, Besner, \& Smilek, 2014) on PM components. As an illustration the FRN was found reduced during mind-wandering periods compared to on-task periods in the study of Kam and colleagues
(2012). Such results could help to characterize one aspect of the OOTL phenomenon at a physiological level. Furthermore, this degradation of the performance monitoring activity could serve as a physiological marker of the OOTL phenomenon.

Nevertheless, several limits still remain. Firstly, most studies on system supervision use easy laboratory tasks, which are not ecological at all and cannot be compared to the type of supervision we can find in human-system interactions with highly automated processes. Then, nearly all studies which have been performed require actions from the participants. Yet, one of the problematic of system supervision and the OOTL phenomenon is that operators are most often asked to passively supervise the system, without requiring any actions. Finally, the neural correlates of the PM activity are currently measured through the repetition of several identical trials which are then averaged to increase the statistical validity of the results. A huge amount of data is usually needed to detect the ERPs and their neural generators. This type of configuration is not feasible in an everyday life situation (for a broader description of the limits of system PM measures, see Somon et al., 2017).

\subsection{The Mind Wandering phenomenon}

We have previously argued that vigilance failure is a key component of OOTL situations (Amalberti, 1999; Sarter and Woods, 1995b). Reports of incidents in aviation have notably illustrated the role of vigilance failure in human error. For example, Mosier et al. (1994) examined NASA's Aviation Safety Reporting System (ASRS) database and found that $77 \%$ of the incidents in which over reliance on automation was suspected involved a probable vigilance failure. Similarly, Gerbert and Kemmler (1986) studied German aviators' anonymous responses to questionnaires about automation related incidents and reported failures of vigilance as the largest contributor to human error. Nowadays, there is some consensus for the existence of a degradation of human operator vigilance in interaction with highly automated system.

Vigilance refers to the ability of organisms to maintain their focus of attention and to remain alert to stimuli over prolonged periods of time (Davies \& Parasuraman, 1982; Parasuraman, 1986; Warm, 1984a, 1993). Traditionally, the vigilance decrement was thought to be caused 
by a decline in arousal brought about by the under stimulating nature of vigilance tasks (Frankmann \& Adams, 1962; Heilman, 1995; Loeb \& Alluisi, 1984; Welford, 1968). According to that view, repetitious and monotonous aspects of vigilance tasks suppress activity in brain systems necessary to maintain continued alertness. As a result, the efficiency with which signals are detected is reduced. Numerous studies have confirmed that, at least during some phases of flight, automation can indeed help lower pilot workload and free up time (Casner, 2009; Roscoe, 1992; Wiener, 1989).

Parasuraman and Davies (1977; see also Parasuraman, 1976, 1979) have proposed a different explanation of this vigilance failure, the attentional resource theory (see Fisk \& Scerbo, 1987; Fisk \& Schneider, 1981; Kahneman, 1973; Wickens, 1984). In this context, vigilance tasks are thought to impose considerable mental workload (Helton and Warm, 2008; Warm et al., 1996, 2008) and the vigilance decrement reflects the depletion of information processing resources or information-processing assets which cannot be replenished in the time available.

These two different interpretations of the vigilance failure point to a decrease in the degradation of the brain activity underlying the vigilance mechanisms. We propose another perception of this vigilance decrement issue based on the relation between OOTL phenomenon and Mind Wandering (MW) episodes. MW is the human mind's propensity to generate thoughts unrelated to the task at hand (Christoff, 2012; Stawarczyk et al., 2012). This phenomenon has three major features: it is experienced by everybody (Killingsworth and Gilbert, 2010), it influences our perception and processing of external stimuli (He et al., 2011), and it can take place either intentionally or unintentionally (Seli et al., 2016; Smallwood and Schooler, 2006). In brain imaging studies, MW is characterized by the activation of the Default Mode Network, a widely distributed brain region comprised of medial prefrontal cortex and the posterior cingulate cortex (Christoff, 2012; Christoff et al., 2009a; Konishi et al., 2015; Mason et al., 2007). Even though MW is thought to facilitate prospection, introspection and problem solving (Smallwood and Schooler, 2006), performance drops in numerous tasks has been observed during MW episodes (Bastian and Sackur, 2013; Berthié et al., 2015; Casner and Schooler, 2013, 2015; Galera et al., 2012; He et al., 2011; Schad et al., 2012; Yanko and Spalek, 2014). Several aspects outline a possible role of MW in OOTL in highly reliable automated environments (for a review, see Gouraud, Delorme, \& Berberian, 2017a).

First, MW is by definition associated to decreased vigilance (Oken et al., 2006; Braboszcz \& Delorme, 2011). The MW phenomenon diverts attention from immediate goals (Golchert et al., 2016; Seli et al., 2016). An individual who is MW is, at least, partly decoupled from his or her environment and shows little to no reaction to external stimuli (Schooler et al., 2014). Although the processes behind this vigilance drop are debated (McVay and Kane, 2009), MW has been proposed as a relevant measure of the vigilance decrement (see for example Farley et al., 2013).

Moreover, MW is known to occur in monotonous or boring environments, where operators struggle to keep a high vigilance levels. Particularly, MW is more likely if the subject is at rest or performing less demanding tasks, such as reading, driving on a familiar route or piloting an airplane with autopilot engaged (Eastwood et al., 2012). Several studies by Cheyne, Carriere and Smilek (Carriere et al., 2008; Cheyne et al., 2006) point a relation between MW and boredom. Using questionnaires, they found a significant increase in everyday attentional failures for individuals more prone to boredom. MW might actually help to cope with boredom (Schooler et al., 2014). Interestingly, Cummings et al. (2015) recently warned about a possible increase in boredom when integrating higher levels of automation. In that sense, it is not surprising that time spent on task also increases MW (McVay and Kane, 2009; Smallwood et al., 2006; Thomson et al., 2014).

Finally, it has been established that MW creates a sensory attenuation (Blanchard et al., 2014; He et al., 2011), lowers processing of external information (Braboszcz and Delorme, 2011; O'Connell et al., 2009) and decreases performances (Schad et al., 2012; Smallwood et al., 2008; Feng et al., 2013).

All of those aspects pose potential threats for any critical task requiring sustained attention. Studies point MW as a possible cause of many driving accidents (Galera et al., 2012), plane crashes (Casner and Schooler, 2013) and medical errors (van Charante et al., 1993). 
Recently, a link between automation and MW has been proposed. Casner and Schooler (2014) conducted a study where pilots were instructed to handle the approach - flight phase before landing - in a simulator by following beacons at altitudes given by the ATCo. Probes inquired about their state of mind at predetermined times while pilots had to report their position to the ATCo. They reported that when using higher levels of automation, pilots were more prone to MW when they had no interaction with the system and when the previous call had been made. Time saved by automation, which should normally be used to plan the flight, was instead fulfilled by taskunrelated thoughts. Casner and Schooler (2014) highlighted the blurry situation of pilots left with spare time and no guidance about how to actively monitor the automation. This spare time could encourage operators to think about unrelated concerns, and drive them away from important matters such as their current position or the mode of the system.

In a recent study, we have explored the impact of automation on mind wandering in an operational environment (see Gouraud, Delorme, \& Berberian, 2017b). In this preliminary study, participants performed an obstacle avoidance task in manual and automated conditions in 2 sessions of 45 minutes each. An unmanned air vehicle (UAV) depicted as a plane seen from above stayed at the center of a $2 \mathrm{D}$ radar screen and moved following waypoints with clusters of obstacles along the way (every $45 \mathrm{~s}$ on average). The participants were instructed to control the movements of the UAV to avoid obstacles. Two conditions were proposed. The first one was the "manual" condition and required participants to manually avoid obstacles. The second condition was the "automated" condition. Participants were required to monitor the system avoiding obstacles. Both participants' propensity to mind wander and oculometric measures were collected.

Our results highlighted a significant influence of automation after 20 minutes of task over MW frequency. Particularly, MW frequency largely increases in time in the automated condition whereas no evolution is observed in the manual condition. Complacency could explain this interaction between time and level of automation regarding MW occurrence. Indeed, in our experiment, participants interact with highly reliable system (they encounter no error during the first three blocks). The absence of errors could lead participants to neglect the possibility of errors in the experiment. In this context, their perception of the required workload might evolve: as the automated system does not seem to require their attention to function properly, participants would redirect their cognitive resources towards more personal matters and mindwander more. The higher perceived workload in the manual condition at the end of the session supports our analysis. This position would introduce a third possibility within the overload/underload theory debate (Pattyn, Neyt, Henderickx, \& Soetens, 2008; Warm et al., 2008). Although the task complexity does not change, the operator's perception could evolve based on their trust in the system and their feeling toward the overall situation. This is in line with Casner and Schooler (2015), who demonstrated that cognitive resources freed by automation in peaceful situations are not allocated to task planning but rather to MW. Studies which observed MW increase in low probability signal environment (Berthié et al., 2015; Casner \& Schooler, 2015; Galera et al., 2012) and with time on task (McVay \& Kane, 2009; Smallwood, Baracaia, Lowe, \& Obonsawin, 2003; Smallwood, Riby, Heim, \& Davies, 2006) also support our results. Our analysis of complacency as an explanation is in line with the view of complacency as a multiple-task strategy (Bahner et al., 2008; Moray \& Inagaki, 2000). Operators save cognitive resources allocated to the low-event automated task in order to perform better on another task, which is thought to be interesting or useful.

The exact causal link remains still to be demonstrated. Far from being anecdotal, such a link would allow OOTL research to use theoretical and experimental understanding accumulated on MW. Up to now, MW physiological aspects are more understood than OOTL, while MW influence over the operator'sperformance is more precisely assessed. More interestingly, the large range of MW markers could be used to detect OOTL situations and help us to understand the underlying dynamics. As an illustration, Braboszcz and Delorme (2011) have recently studied the brain dynamics associated with mind wandering. They have shown that mind wandering episodes are associated with an increase in theta $(4-7 \mathrm{~Hz})$ and delta $(2-3.5 \mathrm{~Hz})$ EEG activity and a decrease in alpha $(9-11 \mathrm{~Hz})$ and beta (15-30 Hz) EEG activity (see Figure 2). Others have pointed pupil size Grandchamp, Braboszcz, \& Delorme, 2014), 
heart rate and skin conductance response (Smallwood, O'Connor, Sudbery, \& Obonsawin, 2007) variations as potential markers of MW. Such physiological characterization could be used as physiological precursor of the OOTL phenomenon.

An interesting approach could be the use of such pattern of activity as marker of OOTL phenomenon for adaptive automation. Designing systems capable of detecting and countering MW might highlight the reason why we all mind wander. Eventually, the expected outcome is a model of OOTL-MW interactions which could be integrated into autonomous systems. This system description echoes recent advances towards adaptive and communicative automation (Cassell and Vilhjálmsson, 1999; May and Baldwin, 2009). Adaptive systems could detect and react to operators' state of mind, including mood, motivation, fatigue, or arousal. The signals sent, information displayed, and levels of automation could be adjusted by the system to maximize situation awareness and vigilance. These systems could detect MW and decide whether it should be stopped or allowed depending on the situation and the characteristics of the episode. Thus, the operator could benefit from MW's advantages while having a reduced risk of experiencing OOTL issues. The benefits of keeping an operator always in the loop could demonstrate that humans can still be useful in safety favoring industries.

The use of MW findings could be a huge step towards understanding and countering OOTL's deleterious effects on human performance. However, many parts of MW remain largely unknown and could limit the transposition. For example, it is not clear whether MW is a binary state or a gradual mechanism yet. Cheyne et al (2009) proposed a three-level model of MW by postulating that response time degradation-slowing, anticipation and omissions - could each correspond to a different level. This hypothesis is empirically confirmed by our ability to perform everyday tasks accurately in spite of MW. For example, driving is still possible with MW (Lerner et al., 2015; Qu et al., 2015) even though it does affect performance. Investigating this possibility will require changing paradigms. While the probes so far have asked the subject to report their state of mind in a binary fashion, we need to use a scale and compare its results to the evolution of psychophysiological markers. Another critical issue refers to our ability to detect MW in ecological environment. Probes, even though the most common measure of $\mathrm{MW}$, remains intrusive measures difficult to apply in ecological task (Berthié et al. 2015). Moreover, real-time detection based on physiological signals is still difficult. Several classifiers has been proposed, using galvanic skin conductance (Blanchard et al, 2014), heart rate variability (Pham and Wang, 2015) or oculometric measure (Bixler and D'Mello (2014, 2015). However, the results obtained with these different classifiers are far from allowing us to detect all MW occurrences. These biomarkers are both, generally, non univocal to infer on human activity and difficult to acquire in ecological environment. Furthermore, the reliability and stability of these methods within and across individuals needs to be more rigorously tested (Wang et al., 2011; Christensen et al., 2012). To go further, multimodal classifiers and triangulation (of methods and data) should certainly be used. Finally, although using neuroimaging to monitor the participants' attention seems promising, artifacts on the EEG signal make online processing difficult. A major issue concerns the detection and removal of artifacts in real time.

\subsection{The sense of agency}

As previously discussed, one result of automation is the introduction of new coordination demands and the emergence of new types of issues due to failures in the human-machine relationship. In this context, the main problem with automation is not the presence of automation, but rather its inappropriate design (Norman, 1990). Where designers really need guidance today is how to support the coordination between people and automation, not only in foreseeable standard situations, but also during novel, unexpected circumstances. In this sense, it was recently proposed that the key for designers is to "socialize our interactions with technology" (Norman, 2010). How to design collaborative agent has known a particular interest during the last years (Christoffersen \& Woods, 2000; Klein \& al, 2004; Hoc \& Carlier, 2002, Hoc, 2007; Zimmermann \& al., 2014; Dragan, Lee, $\&$ Srinivasa, 2013). Here, we consider that the recent developments in the science of agency provide new conceptual tools and measures to analyze agent-system interactions.

The mechanisms underlying the experience of intentional causation and the sense of control 
of our own actions are the first concern of the science of agency (Pacherie, 2007). In other words, agency corresponds to our capacity to make things happens, to change the world thorough our action. Interestingly, several authors argue for the existence of a spontaneous and pre-reflexive 'we-identity' formation that occurs when two humans are cooperating (Obhi \& Hall, 2011; Crivelli \& Balconi, 2010). This new agentive identity leads individuals to experience agency as soon as one of the two had performed a goaldirected action. Then, in this particular context of joint actions, the sense of control does not rely anymore on the specific contributions of each individual but rather on the group performance.

What makes our understanding of agency especially relevant is the fact that several studies related to agency in dyads tend to highlight a clear distinction between the sense of agency felt by an agent when he is interacting with another human versus with a machine (Glasauer, Huber, Basili, Knoll, \& Brandt, 2010; Obhi \& Hall, 2011b; Poonian \& Cunnington, 2013; Sahaï, Pacherie, Grynszpan, \& Berberian, 2017a; Wohlschläger, Engbert, et al., 2003; Wohlschläger, Haggard, et al., 2003). Such difficulties to develop a sense of we-agency with artificial agents remain still without clear explanations. A better understanding of the role played by the sense of agency may therefore provide a useful framework for thinking about interactions with automated technology and particularly to optimize human-automation interaction.

Although the mental processes contributing to the sense of agency are not fully understood at this time, the different approaches propose that we derive a sense of being the agent for our own actions by a cognitive mechanism that computes the discrepancies between the predicted consequences of our own actions' and the actual consequences of these actions, just as action control models (see Blakemore, Wolpert, \& Frith, 2002; Wegner, 2002). Interestingly, it has been proposed that the cognitive mechanisms that are involved in the sense of agency during individual actions are of the same kind as those that underlie the sense of agency during joint-actions of other humans (Pacherie, 2012). In these different models, prediction appears as a first concern for the experience of agency during our interactions with peers (for a review, see Sahaï, et al., 2017a). Particularly, it has been assumed that before action execution (self-generated or observed other-generated), the mirror system could simulate the motor command so that the simulation content can be used to predict the consequences of the action, enhancing action control or implicit action understanding (Pacherie \& Dokic, 2006). More specifically, this kind of motor simulation supports our understanding of the low-level motor intentions of others, i.e., the type of action he or she is doing (Rizzolatti, Fogassi, \& Gallese, 2001), and also our understanding of others' higher-level prior intentions, i.e., why he or she is doing this action (Iacoboni, et al., 2005).

Impairment in prediction of artificial agent behaviors has been proposed as a potential contributor of the difficulty to develop joint agency when interacting with machines. The existence of deep discrepancies between the robot real state and the operator's perception of its state is well documented (Norman, 1990). In particular, while humans are typically able to represent the actions of their human partners and engage themselves in successful human interactions, they experience difficulties in mirroring and fitting with machine-generated actions (Kuz et al., 2015; Obhi \& Hall, 2011b; Wohlschläger, Engbert, \& Haggard, 2003; Wohlschläger, Haggard, Gesierich, \& Prinz, 2003).

To illustrate such difficulties, we have recently investigated the Simon Social effect when engaged in a human-machine interaction (Sahaï, Pacherie, Grynszpan, \& Berberian, 2017b). The standard Simon effect refers to the interference effect that occurs when an individual has to respond with the right or left hand to a stimulus presented in an incongruent mapping location compared to a congruent mapping location (Simon \& Small, 1969). A conflict occurs because two actions representations (i.e. the correct action to perform and the spatially-induced automatic activated action) are activated and the participant has to solve the conflict in order to select the accurate behavior. Using a joint Simon task, Sebanz, Knoblich, \& Prinz, (2003) have found evidence of a social Simon effect, suggesting that during joint actions, actions of others are represented in our own motor plan (Sebanz, Knoblich, \& Prinz, 2003). This paradigm has been replicated by Sahaï and colleagues (2017) with a human confederate versus a desktop computer partner. Interestingly, the authors found a compatibility effect (faster reaction times for the compatible trials compared to the incompatible trials) only in case of human confederate, thus supporting 
the idea that the presence of artificial agent lead to an impairment in prediction. In addition, the results show that this impairment go along with a decrease in joint-agency in case of the human-machine interaction in comparison to the human-human interaction. In other words, it seems that the automatic representation of the partner's action does not appear when we interact with an automated artificial agent. Consistently, using an aircraft supervision task with different autopilot settings, it has been shown that both at the implicit and explicit levels, individuals' sense of agency drastically decrease when the automation level is extended (Berberian, Sarrazin, Le Blaye, \& Haggard, 2012).

The question remains how system designers could compensate this impairment in prediction of artificial agent behaviors. In this context, we assume that the implementation of biological motion laws in anthropomorphic robot could be an interesting option. Indeed, such implementation could allow a better implicit understanding of the machines' actions thanks to observer's action/observation matching system, with the help of his or her own motor experience. Considering that operators interpret the intentions and the action outcomes of a system with their own "cognitive toolkit", to implement human-like motions in robot can make it easier for humans to predict the machine actions. As prior intentions are embodied in kinematics, by simulating observed other-generated actions, it is possible to understand what the observed agent intends to do with the help of our own motor experience (Georgiou, Becchio, Glover, \& Castiello, 2007; Iacoboni et al., 2005). In addition to make automated systems more predictable (i.e. to optimize intention understanding from early action observation), maximizing action legibility (i.e. to facilitate action reading from kinematics) might be another requirement for machine-generated action better understanding (Dragan, Lee, \& Srinivasa, 2013). Finally, even though knowledge from social robotic research keep trying to understand how to optimize the interactions between social robots and humans, investigations about the sense of agency during these joint actions are still missing. Optimizing human robot interaction is a crucial issue for the design of future technological systems given that humans will be increasingly involved in tasks where they need to interact with highly automated environment. The science of agency can help a better comprehension about how individuals can have a sense of control over these automata.

\section{Conclusion}

In the past decades, automation has become increasingly present in our daily life. This evolution has dramatically changed the nature of human work and induced many safety and performance issues associated with it stemming from the human out-of-the-loop performance problem. Understanding the characteristics and the dynamics of this transformation is vital for successful design of new automated systems.

In this paper, we have proposed a new vision of the transformation induced by automation, based on recent insight in the domain of the neurosciences. The introduction of neuroscientific concepts aims at bringing an innovative contribution to the understanding of the OOTL performance problem and open new approaches to characterize, monitor and compensate such phenomenon. In this paper, we have introduced different concepts Performance Monitoring Function, Mind Wandering, and Sense of Agency - and described how these concepts could increase our understanding of the OOTL phenomenon. Preliminary results have been introduced and demonstrate the relevance of such approach.

To effectively understand how humans interact with work systems, it is not only important to ask how well they perform, but also why they perform a certain way. Neuroergonomics could help fill in the gaps on the neural bases of cognitive performance that were left unanswered with traditional ergonomic assessments. However, applicability and feasibility of neuroscientific concepts, methods and tools need to be questioned. Much of the research presented in this paper is confined to rather small controlled experiments, with the presumption that the findings could be generalized to other settings. We have pointed that such models and methods suffer from a variety of problems that limit their usefulness in ecological settings. Future works should overcome these barriers to make possible the transposition of these models to the humanautomation interaction problem. 


\section{Vitae}

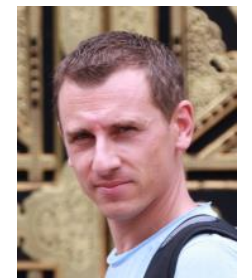

Bruno Berberian is currently working as a research engineer at the ONERA center of Salon de Provence (France). He obtained his Ph.D. in Human Movement Science, from the University of Mediterranée in 2007. After a post-doctoral position in the Consciousness, Cognition and Computation group (Belgium), he joined ONERA in 2009. He is now studying how cognitive neuroscience theories and models apply to performance problems in Aeronautics.

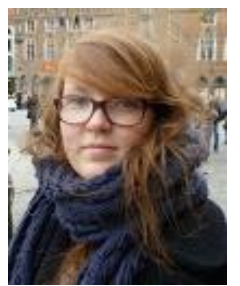

Bertille SOMON is currently working as a $\mathrm{PhD}$ student at the ONERA center of Salon de Provence (France). She obtained a Biomedical Engineering Master's degree in Bioengineering and Innovation in Neurosciences in 2015 at the University of Paris Descartes. She is now studying the degradation of the performance monitoring function when interacting with automated system.

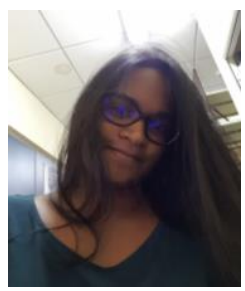

Aïsha Sahai is currently working as a $\mathrm{PhD}$ student at the ONERA center of Salon de Provence (France). She obtained a Master's degree in Psychology of Cognitive Processes in 2015 at the University Lille 3 . She is now studying the impact of system predictability on human machine cooperation.

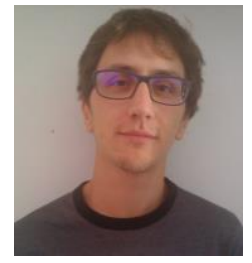

Jonas GOURAUD is currently working as a $\mathrm{PhD}$ student at the ONERA center of Salon de Provence (France). He obtained in 2015 a dual diploma Master and Engineering Degree in Human-Machine Interaction at ENAC (French National Aeronautics School, Toulouse, France). He is now studying the Mind Wandering phenomenon and its link with system automation.

\section{References}

1 Amalberti, R. (1999). Automation in aviation: A human factors perspective. Handbook of Aviation Human Factors, 173-192.

2 Bagheri, N., \& Jamieson, G. A. (2004). Considering subjective trust and monitoring behavior in assessing automation-induced "complacency." Human Performance, Situation Awareness, and Automation: Current Research and Trends, 54-59.

3 Bahner, J. E., Hüper, A.-D., \& Manzey, D. (2008). Misuse of automated decision aids: Complacency, automation bias and the impact of training experience. International Journal of HumanComputer Studies, 66(9), 688-699.

4 Bailey, N. R., \& Scerbo, M. W. (2007). Automation-induced complacency for monitoring highly reliable systems: the role of task complexity, system experience, and operator trust. Theoretical Issues in Ergonomics Science, 8(4), 321348.

5 Bainbridge, L. (1983). Ironies of automation. Automatica, 19(6), 775-779.

6 Bannon, L. (1991). From human factors to human actors: The role of psychology and human-computer interaction studies in system design. Design at Work: Cooperative Design of Computer Systems, $25,44$.

7 Bastian, M., \& Sackur, J. (2013). Mind wandering at the fingertips: automatic parsing of subjective states based on response time variability. Frontiers in Psychology, 4.

8 Berberian, B., Sarrazin, J. C., Le Blaye, P., \& Haggard, P. (2012). Automation technology and sense of control: a window on human agency. PLoS One, 7(3), e34075.

9 Berthié, G., Lemercier, C., Paubel, P.-V., Cour, M., Fort, A., Galéra, C., ... Maury, B. (2015). The restless mind while driving: drivers' thoughts behind the wheel. Accident Analysis \& Prevention, 76, 159-165.

10 Billings, C. E. (1991). Human-centered aircraft automation: A concept and guidelines. 
11 Billings, C. E. (1996). Human-centered aviation automation: Principles and guidelines.

12 Billings, C. E. (1997). Aviation automation: The search for a humancentered approach.

13 Bixler, R., and D'Mello, S. (2014). "Toward Fully Automated PersonIndependent Detection of Mind Wandering," in User Modeling, Adaptation, and Personalization (Springer), 37-48.

14 Bixler, R., and D'Mello, S. (2015). Automatic gaze-based user-independent detection of mind wandering during computerized reading. User Model. UserAdapt. Interact. doi:10.1007/s11257-0159167-1.

15 Blakemore, S. J., Wolpert, D. M., \& Frith, C. D. (2002). Abnormalities in the awareness of action. Trends in cognitive sciences, 6(6), 237-242.

16 Blanchard, N., Bixler, R., Joyce, T., \& D’Mello, S. (2014). Automated physiological-based detection of mind wandering during learning. In Intelligent Tutoring Systems (pp. 55-60). Springer. Retrieved from

17 Bolstad, C. A., \& Endsley, M. R. (2000). The effect of task load and shared displays on team situation awareness (Vol. 44, pp. 189-192). Presented at the proceedings of the human factors and ergonomics society annual meeting, SAGE Publications Sage CA: Los Angeles, CA.

18 Bonini, F., Burle, B., Liegeois-Chauvel, C., Regis, J., Chauvel, P., \& Vidal, F. (2014). Action Monitoring and Medial Frontal Cortex: Leading Role of Supplementary Motor Area. Science, 343(6173), 888-891.

19 Braboszcz, C., \& Delorme, A. (2011). Lost in thoughts: neural markers of low alertness during mind wandering. Neuroimage, 54(4), 3040-3047.

20 Carp, J., Halenar, M. J., Quandt, L. C., Sklar, A., \& Compton, R. J. (2009). Perceived similarity and neural mirroring: Evidence from vicarious error processing. Social Neuroscience, 4(1), 85-96.

21 Carriere, J. S. A., Cheyne, J. A., and Smilek, D. (2008). Everyday attention lapses and memory failures: The affective consequences of mindlessness. Conscious. Cogn. 17, 835-847.

22 Casner, S. M. (2009). Perceived vs. measured effects of advanced cockpit systems on pilot workload and error: Are pilots' beliefs misaligned with reality? Applied Ergonomics, 40(3), 448-456.

23 Casner, S. M., \& Schooler, J. W. (2013). Thoughts in Flight Automation Use and Pilots' Task-Related and Task-Unrelated Thought. Human Factors: The Journal of the Human Factors and Ergonomics Society, 0018720813501550.

24 Casner, S. M., \& Schooler, J. W. (2014). Thoughts in flight: Automation use and pilots' task-related and task-unrelated thought. Human factors, 56(3), 433-442.

25 Casner, S. M., \& Schooler, J. W. (2015). Vigilance impossible: Diligence, distraction, and daydreaming all lead to failures in a practical monitoring task. Consciousness and Cognition, 35, 33-41.

26 Cassell, J., and Vilhjálmsson, H. (1999). Fully embodied conversational avatars: Making communicative behaviors autonomous. Auton. Agents Multi-Agent Syst. 2, 45-64.

27 Castaño, D., \& Parasuraman, R. (1999). Manipulation of pilot intent under Free Flight- A prelude to not-so-free flight (pp. 170-176). Presented at the International Symposium on Aviation Psychology, 10 th, Columbus, $\mathrm{OH}$.

28 Cheyne, J. A., Carriere, J. S. A., and Smilek, D. (2006). Absent-mindedness: Lapses of conscious awareness and everyday cognitive failures. Conscious. Cogn. 15, 578-592. doi:10.1016/j.concog.2005.11.009.

29 Chiappe, D. L., Strybel, T. Z., \& Vu, K.-P. L. (2012). Mechanisms for the acquisition of situation awareness in situated agents. Theoretical Issues in Ergonomics Science, 13(6), 625-647.

30 Chiappe, D., Vu, K.-P. L., \& Strybel, T. (2012). Situation awareness in the NextGen air traffic management system. International Journal of HumanComputer Interaction, 28(2), 140-151.

31 Christoffersen, K., \& Woods, D. D. (2002). How to make automated systems team players. In Advances in human performance and cognitive engineering 
research (pp. 1-12). Emerald Group Publishing Limited.

32 Christoff, K. (2012). Undirected thought: Neural determinants and correlates. Brain Research, 1428, 51-59.

33 Christoff, K., Gordon, A. M., Smallwood, J., Smith, R., \& Schooler, J. W. (2009). Experience sampling during fMRI reveals default network and executive system contributions to mind wandering. Proceedings of the National Academy of Sciences, 106(21), 8719-8724.

34 Crivelli, D., \& Balconi, M. (2010). Agency and inter-agency, action and joint action: Theoretical and neuropsychological evidence. In Neuropsychology of the Sense of Agency, ed. M. Balconi (Springer), chap. 6. 107122.

35 Dao, A.-Q. V., Brandt, S. L., Battiste, V., Vu, K.-P. L., Strybel, T., \& Johnson, W. W. (2009). The impact of automation assisted aircraft separation on situation awareness (pp. 738-747). Presented at the Symposium on Human Interface, Springer.

36 Davies, D. R., \& Parasuraman, R. (1982). The psychology of vigilance. Academic Press. Retrieved from

37 Degani, A., \& Heymann, M. (2000). Pilotautopilot interaction: A formal perspective. Abbott et al.[1], 157-168.

38 Dekker, S., \& Hollnagel, E. (2004). Human factors and folk models. Cognition, Technology \& Work, 6(2), 7986.

39 Dekker, S. W. A., \& Woods, D. D. (2002). MABA-MABA or Abracadabra? Progress on Human-Automation Co-ordination. Cognition, Technology \& Work, 4(4), 240-244.

40 Dragan, A. D., Lee, K. C., \& Srinivasa, S. S. (2013, March). Legibility and predictability of robot motion. In HumanRobot Interaction (HRI), 2013 8th ACM/IEEE International Conference on (pp. 301-308). IEEE.

41 Durso, F. T., Hackworth, C. A., Truitt, T. R., Crutchfield, J., \& Nikolic, D. (1999). Situation Awareness As a Predictor of Performance in En Route Air Traffic Controllers. DTIC Document.
42 Durso, F. T., Rawson, K. A., \& Girotto, S. (2007). Comprehension and situation awareness. Handbook of Applied Cognition, 2, 163-193.

43 Eastwood, J. D., Frischen, A., Fenske, M. J., \& Smilek, D. (2012). The Unengaged Mind: Defining Boredom in Terms of Attention. Perspectives on Psychological Science, 7(5), 482-495.

44 Endsley, M. R. (1995). Toward a theory of situation awareness in dynamic systems. Human Factors, 37(1), 32-64.

45 Endsley, M. R. (1996). Automation and Situation Awareness. In Automation and human performance: Theory and applications (pp. 163-181).

46 Endsley, M. R. (1999). Level of automation effects on performance, situation awareness and workload in a dynamic control task. Ergonomics, 42(3), 462-492.

47 Endsley, M. R. (2016). Designing for situation awareness: An approach to usercentered design. CRC press.

48 Endsley, M. R. (2017). From here to autonomy: lessons learned from humanautomation research. Human Factors, 59(1), 5-27.

49 Endsley, M. R., \& Kiris, E. O. (1995). The Out-of-the-Loop Performance Problem and Level of Control in Automation. Human Factors: The Journal of the Human Factors and Ergonomics Society, 37(2), 381-394.

50 Endsley, M. R., \& Rodgers, M. D. (1998). Distribution of Attention, Situation Awareness \& Workload in a Passive Air Traffic Control Task. Air Traffic Control Quarterly, 6(1), 21-44.

51 Falkenstein, M., Hohnsbein, J., Hoormann, J., \& Blanke, L. (1991). Effects of crossmodal divided attention on late ERP components. II. Error processing in choice reaction tasks. Electroencephalography and Clinical Neurophysiology, 78(6), 447-455.

52 Farley, J., Risko, E. F., \& Kingstone, A. (2013). Everyday attention and lecture retention: the effects of time, fidgeting, and mind wandering. Frontiers in Psychology. 
53 Farrell, S., \& Lewandowsky, S. (2000). A connectionist model of complacency and adaptive recovery under automation. Journal of Experimental Psychology: Learning, Memory, and Cognition, 26(2), 395.

54 Feng, S., D’Mello, S., \& Graesser, A. C. (2013). Mind wandering while reading easy and difficult texts. Psychon. Bull. Rev. 20, 586-592.

55 Fisk, A. D., \& Scerbo, M. W. (1987). Automatic and control processing approach to interpreting vigilance performance: A review and reevaluation. Human Factors, 29(6), 653-660.

56 Fisk, A. D., \& Schneider, W. (1981). Control and automatic processing during tasks requiring sustained attention: A new approach to vigilance. Human Factors, 23(6), 737-750.

57 Flemisch, F., Heesen, M., Hesse, T., Kelsch, J., Schieben, A., \& Beller, J. (2012). Towards a dynamic balance between humans and automation: authority, ability, responsibility and control in shared and cooperative control situations. Cognition, Technology \& Work, 14(1), 3-18.

58 Frankmann, J. P., \& Adams, J. A. (1962). Theories of vigilance. Psychological Bulletin, 59(4), 257.

59 Funk, K., Lyall, B., Wilson, J., Vint, R., Niemczyk, M., Suroteguh, C., \& Owen, G. (1999). Flight Deck Automation issues. The International Journal of Aviation Psychology, 9(2), 109-123.

60 Gaines, B. R., McCarthy, J., Fallon, E., \& Bannon, L. (2000). Function Allocation (Special Issue). International Journal of Human-Computer Studies, 52(2), 191383.

61 Galera, C., Orriols, L., M'Bailara, K., Laborey, M., Contrand, B., RibereauGayon, R., ... Lagarde, E. (2012). Mind wandering and driving: responsibility case-control study. BMJ, 345(dec13 8), e8105-e8105.

62 Galster, S. M., Duley, J. A., Masalonis, A. J., \& Parasuraman, R. (2001). Air Traffic Controller Performance and Workload Under Mature Free Flight: Conflict Detection and Resolution of Aircraft Self-
Separation. The International Journal of Aviation Psychology, 11(1), 71-93.

63 Gentsch, A., Ullsperger, P., \& Ullsperger, M. (2009). Dissociable medial frontal negativities from a common monitoring system for self- and externally caused failure of goal achievement. NeuroImage, 47(4), 2023-2030.

64 Gerbert, K., \& Kemmler, R. (1986). The causes of causes: determinants and background variables of human factor incidents and accidents. Ergonomics, 29(11), 1439-1453.

65 Glasauer, S., Huber, M., Basili, P., Knoll, A., \& Brandt, T. (2010). Interacting in time and space: Investigating humanhuman and human-robot joint action. In RO-MAN, 2010 IEEE, 252-257. IEEE.

66 Golchert, J., Smallwood, J., Jefferies, E., Seli, P., Huntenburg, J. M., Liem, F., et al. (2016). Individual variation in intentionality in the mind-wandering state is reflected in the integration of the default-mode, fronto-parietal, and limbic networks. NeuroImage. doi:10.1016/j.neuroimage.2016.11.025.

67 Gouraud, J., Delorme, A. \& Berberian, B. (2017a). Autopilot, Mind-Wandering and the Out-Of-the-Loop Performance Problem. Front. Neurosci. doi : 10.3389/fnins.2017.00541

68 Gouraud, J., Delorme, A. \& Berberian, B. (2017b). A Preliminary Study on the Influence of Automation over Mind Wandering Frequency in Sustained Attention. In Proceedings of the 29th Annual European Conference on Cognitive Ergonomics

69 Grandchamp, R., Braboszcz, C., \& Delorme, A. (2014). Oculometric variations during mind wandering. Frontiers in psychology, 5.

70 He, J., Becic, E., Lee, Y.-C., \& McCarley, J. S. (2011). Mind Wandering Behind the Wheel: Performance and Oculomotor Correlates. Human Factors: The Journal of the Human Factors and Ergonomics Society, 53(1), 17-21.

71 Helton, W. S., \& Warm, J. S. (2008). Signal salience and the mindlessness theory of vigilance. Acta Psychologica, 129(1), 18-25.

72 Hoc, J. M. (2007). Human and automation: a matter of cooperation. In 
HUMAN 07 (pp. 277-285). Université de Metz.

73 Hoc, J. M., \& Carlier, X. (2002). Role of a common frame of reference in cognitive cooperation: sharing tasks between agents in air traffic control. Cognition, Technology \& Work, 4(1), 37-47.

74 Holroyd, C. B., \& Coles, M. G. H. (2002). The neural basis of human error processing: Reinforcement learning, dopamine, and the error-related negativity. Psychological Review, 109(4), 679-709.

75 Hutchins, E. (1995). How a cockpit remembers its speeds. Cognitive Science, 19(3), 265-288.

76 Iacoboni, M., Molnar-Szakacs, I., Gallese, V., Buccino, G., Mazziotta, J.C., \& Rizzolatti, G. (2005) Grasping the Intentions of Others with One's Own Mirror Neuron System. PLoS Biol 3(3): e79.

77 Jääskeläinen, I. P., Halme, H.-L., Agam, Y., Glerean, E., Lahnakoski, J. M., Sams, M., ... Manoach, D. S. (2016). Neural mechanisms supporting evaluation of others' errors in real-life like conditions. Scientific Reports, 6, 18714.

78 Kaber, D. B., \& Endsley, M. R. (1997). Out-of-the-loop performance problems and the use of intermediate levels of automation for improved control system functioning and safety. Process Safety Progress, 16(3), 126-131.

79 Kaber, D. B., \& Endsley, M. R. (2004). The effects of level of automation and adaptive automation on human performance, situation awareness and workload in a dynamic control task. Theoretical Issues in Ergonomics Science, 5(2), 113-153.

80 Kahneman, D. (1973). Attention and effort (Vol. 1063). Prentice-Hall Englewood Cliffs, NJ.

81 Kam, J. W. Y., Dao, E., Blinn, P., Krigolson, O. E., Boyd, L. A., \& Handy, T. C. (2012). Mind wandering and motor control: off-task thinking disrupts the online adjustment of behavior. Frontiers in Human Neuroscience, 6. https://doi.org/10.3389/fnhum.2012.00329

82 Killingsworth, M. A., \& Gilbert, D. T. (2010). A Wandering Mind Is an Unhappy Mind. Science, 330(6006), 932-932.
83 Klein, G., Woods, D. D., Bradshaw, J. M., Hoffman, R. R., \& Feltovich, P. J. (2004). Ten challenges for making automation a“ team player" in joint human-agent activity. IEEE Intelligent Systems, 19(6), 91-95.

84 Koban, L., Pourtois, G., Vocat, R., \& Vuilleumier, P. (2010). When your errors make me lose or win: Event-related potentials to observed errors of cooperators and competitors. Social Neuroscience, 5(4), 360-374.

85 Kuz, S., Petruck, H., Heisterüber, M., Patel, H., Schumann, B., Schlick, C. M., \& Binkofski, F. (2015). Mirror Neurons and Human-robot Interaction in Assembly Cells. Procedia Manufacturing, 3, 402408.

86 Lee, J. D. (2006). Human factors and ergonomics in automation design. Handbook of Human Factors and Ergonomics, Third Edition, 1570-1596.

87 Lee, J. D., \& See, K. A. (2004). Trust in automation: Designing for appropriate reliance. Human Factors, 46(1), 50-80.

88 Lerner, N., Baldwin, C., Higgins, J. S., Lee, J., and Schooler, J. (2015). Mind Wandering While Driving: What Does it Mean and What do we do about it? Proc. Hum. Factors Ergon. Soc. Annu. Meet. 59, 1686-1690.

89 Loeb, M., \& Alluisi, E. A. (1984). Theories of vigilance. Sustained Attention in Human Performance, 179-205.

90 Lorenz, B., Di Nocera, F., Roettger, S., \& Parasuraman, R. (2002). Automated fault management in a simulated space flight micro-world. Aviation, Space, \& Environmental Medicine, 73, 886-897.

91 Mackworth, N. H. (1948). The breakdown of vigilance during prolonged visual search. Quarterly Journal of Experimental Psychology, 1(1), 6-21.

92 Manzey, D., Bahner, J. E., \& Hueper, A.D. (2006). Misuse of automated aids in process control: Complacency, automation bias and possible training interventions. In Proceedings of the Human Factors and Ergonomics Society Annual Meeting (Vol. 50, pp. 220-224). Sage Publications Sage CA: Los Angeles, CA.

93 Mason, M. F., Norton, M. I., Van Horn, J. D., Wegner, D. M., Grafton, S. T., \& 
Macrae, C. N. (2007). Wandering minds: the default network and stimulusindependent thought. Science, 315(5810), 393-395.

94 Matthews, G., \& Davies, D. R. (2001). Individual differences in energetic arousal and sustained attention: a dual-task study. Personality and Individual Differences, 31(4), 575-589.

95 May, J. F., \& Baldwin, C. L. (2009). Driver fatigue: The importance of identifying causal factors of fatigue when considering detection and countermeasure technologies. Transp. Res. Part F Traffic Psychol. Behav. 12, 218-224.

96 McVay, J. C., \& Kane, M. J. (2009). Conducting the train of thought: working memory capacity, goal neglect, and mind wandering in an executive-control task. Journal of Experimental Psychology: Learning, Memory, and Cognition, 35(1), 196.

97 McVay, J. C., \& Kane, M. J. (2010). Does mind wandering reflect executive function or executive failure? Comment on Smallwood and Schooler (2006) and Watkins (2008). Psychological Bulletin.

98 Merat, N., \& Jamson, A. H. (2008). The Effect of Stimulus Modality on Signal Detection: Implications for Assessing the Safety of In-Vehicle Technology. Human Factors: The Journal of the Human Factors and Ergonomics Society, 50(1), 145-158.

99 Methot, L. L., \& Huitema, B. E. (1998). Effects of signal probability on individual differences in vigilance. Human Factors, 40(1), 102-110.

100 Metzger, U., \& Parasuraman, R. (2001). The role of the air traffic controller in future air traffic management: An empirical study of active control versus passive monitoring. Human Factors: The Journal of the Human Factors and Ergonomics Society, 43(4), 519-528.

101 Metzger, U., \& Parasuraman, R. (2005). Automation in Future Air Traffic Management: Effects of Decision Aid Reliability on Controller Performance and Mental Workload. Human Factors: The Journal of the Human Factors and Ergonomics Society, 47(1), 35-49.
102 Miller, C. A., \& Parasuraman, R. (2007). Designing for flexible interaction between humans and automation: Delegation interfaces for supervisory control. Human Factors, 49(1), 57-75.

103 Miltner, W. H. R., Brauer, J., Hecht, H., \& Trippe, R. (2004). Parallel brain activity for self-generated and observed errors.

104 Moray, N. (1986). Monitoring behavior and supervisory control. Handbook of Perception and Human Performance, 40, $1-51$.

105 Moray, N., \& Inagaki, T. (2000). Attention and complacency. Theoretical Issues in Ergonomics Science, 1(4), 354365.

106 Mosier, K. L., Skitka, L. J., \& Korte, K. J. (1994). Cognitive and social psychological issues in flight crew/automation interaction. In Human performance in automated systems: current research and trends (pp. 191197). New York: Cambridge University Press.

107 Neisser, U. (1976). Cognition and reality: Principles and implications of cognitive psychology. WH Freeman/Times Books/Henry Holt \& Co.

108 Nofi, A. A. (2000). Defining and measuring shared situational awareness. CENTER FOR NAVAL ANALYSES ALEXANDRIA VA.

109 Norman, D. A. (1990). The'problem'with automation: inappropriate feedback and interaction, not'over-automation'. Philosophical Transactions of the Royal Society of London. Series B, Biological Sciences, 585-593.

110 Norman, D. A. (1991). Cognitive artifacts. Designing Interaction: Psychology at the Human-Computer Interface, 1, 17-38.

111 Norman, D.A., (2010). Living with complexity. Cambridge, Massachusetts: The MIT Press

112 Obhi, S. S., \& Hall, P. (2011). Sense of agency and intentional binding in joint action. Experimental brain research, 211(3-4), 655.

113 Obhi, S. S., \& Hall, P. (2011). Sense of agency in joint action: Influence of human and computer co-actors. Experimental brain research, 211(3-4), 663. 
114 O’Connell, R. G., Dockree, P. M., Robertson, I. H., Bellgrove, M. A., Foxe, J. J., and Kelly, S. P. (2009). Uncovering the Neural Signature of Lapsing Attention: Electrophysiological Signals Predict Errors up to $20 \mathrm{~s}$ before They Occur. $J$. Neurosci. 29, 8604-8611.

115 O’hanlon, J. F. (1981). Boredom: Practical consequences and a theory. Acta Psychologica, 49(1), 53-82.

116 Oken, B. S., Salinsky, M. C., \& Elsas, S. M. (2006). Vigilance, alertness, or sustained attention: physiological basis and measurement. Clinical Neurophysiology, 117(9), 1885-1901.

117 Onnasch, L., Wickens, C. D., Li, H., \& Manzey, D. (2014). Human performance consequences of stages and levels of automation: An integrated meta-analysis. Human Factors, 56(3), 476-488.

118 Pacherie, E. (2007). The sense of control and the sense of agency. Psyche, 13(1), 130 .

119 Pacherie, E. (2012). Action. In The Cambridge handbook of cognitive science, Cambridge University Press (Ed.), 92-111.

120 Pacherie, E., \& Dokic, J. (2006). From mirror neurons to joint actions. Cognitive Systems Research, 7(2), 101-112.

121 Padrão, G., Gonzalez-Franco, M., Sanchez-Vives, M. V., Slater, M., \& Rodriguez-Fornells, A. (2016). Violating body movement semantics: Neural signatures of self-generated and externalgenerated errors. NeuroImage, 124, 147156.

122 Palmer, E. (1995). Oops, it didn't arm'- A case study of two automation surprises (pp. 227-232). Presented at the International Symposium on Aviation Psychology, 8 th, Columbus, $\mathrm{OH}$.

123 Palmer, E. (1999). Murphi busts an altitude: A murphi analysis of an automation surprise (Vol. 1, p. 4-B). Presented at the Digital Avionics Systems Conference, 1999. Proceedings. 18th, IEEE.

124 Parasuraman, R. (1976). Consistency of individual differences in human vigilance performance: An abilities classification analysis. Journal of Applied Psychology, 61(4), 486.
125 Parasuraman, R. (1979). Memory load and event rate control sensitivity decrements in sustained attention. Science, 205(4409), 924-927.

126 Parasuraman, R. (1986). Vigilance, monitoring, and search.

127 Parasuraman, R., \& Davies, D. (1977). A taxonomic analysis of vigilance performance. In Vigilance (pp. 559-574). Springer.

128 Parasuraman, R., Molloy, R., \& Singh, I. L. (1993). Performance Consequences of Automation-Induced "Complacency." The International Journal of Aviation Psychology, 3(1), 1-23.

129 Parasuraman, R., \& Riley, V. (1997). Humans and Automation: Use, Misuse, Disuse, Abuse. Human Factors: The Journal of the Human Factors and Ergonomics Society, 39(2), 230-253.

130 Parasuraman, R., Sheridan, T. B., \& Wickens, C. D. (2000). A model for types and levels of human interaction with automation. Systems, Man and Cybernetics, Part A: Systems and Humans, IEEE Transactions on, 30(3), 286-297.

131 Parasuraman, R., Sheridan, T. B., \& Wickens, C. D. (2008). Situation awareness, mental workload, and trust in automation: Viable, empirically supported cognitive engineering constructs. Journal of Cognitive Engineering and Decision Making, 2(2), 140-160.

132 Parasuraman, R., \& Wickens, C. D. (2008). Humans: Still vital after all these years of automation. Human Factors: The Journal of the Human Factors and Ergonomics Society, 50(3), 511-520.

133 Parasuraman, R., \& Yantis, S. (1998). The attentive brain. Mit Press Cambridge, MA.

134 Pattyn, N., Neyt, X., Henderickx, D., \& Soetens, E. (2008). Psychophysiological investigation of vigilance decrement: Boredom or cognitive fatigue? Physiology \& Behavior, 93(1-2), 369-378.

135 Pavone, E. F., Tieri, G., Rizza, G., Tidoni, E., Grisoni, L., \& Aglioti, S. M. (2016). Embodying Others in Immersive Virtual Reality: Electro-Cortical Signatures of Monitoring the Errors in the Actions of an Avatar Seen from a First-Person 
Perspective. Journal of Neuroscience, 36(2), 268-279.

136 Pham, P., and Wang, J. (2015). “Attentive Learner: Improving Mobile MOOC Learning via Implicit Heart Rate Tracking," in Artificial Intelligence in Education, eds. C. Conati, N. Heffernan, A. Mitrovic, and M. F. Verdejo (Cham: Springer International Publishing), 367376.

137 Poonian, S. K., \& Cunnington, R. (2013). Intentional binding in self-made and observed actions. Experimental brain research, 229(3), 419.

138 Qu, W., Ge, Y., Xiong, Y., Carciofo, R., Zhao, W., and Zhang, K. (2015). The relationship between mind wandering and dangerous driving behavior among Chinese drivers. Saf. Sci. 78, 41-48.

139 Rizzolatti, G., Fogassi, L., \& Gallese, V. (2001). Neurophysiological mechanisms underlying the understanding and imitation of action. Nature reviews neuroscience, 2(9), 661-670.

140 Roscoe, A. H. (1992). Assessing pilot workload. Why measure heart rate, HRV and respiration? Biological Psychology, 34(2), 259-287.

141 Sahai, E. Pacherie, O. Grynszpan \& B. Berberian. (2017a). Predictive mechanisms are not involved the same way during human-human versus humanmachine interactions: a review. Front Neurorobot.

Doi: 10.3389/fnbot.2017.00052.

142 Sahai, E. Pacherie, O. Grynszpan \& B. Berberian. (2017b). Co-representation of human-generated actions vs. machinegenerated actions: impact on our sense of we-agency? In RO-MAN, 2017 IEEE.

143 Salas, E., Prince, C., Baker, D. P., \& Shrestha, L. (1995). Situation awareness in team performance: Implications for measurement and training. Human Factors, 37(1), 123-136.

144 Sarter, N. B., \& Woods, D. D. (1994). Pilot interaction with cockpit automation II: An experimental study of pilots' model and awareness of the flight management system. The International Journal of Aviation Psychology, 4(1), 1-28.

145 Sarter, N. B., \& Woods, D. D. (1995). How in the world did we ever get into that mode? Mode error and awareness in supervisory control. Human Factors: The Journal of the Human Factors and Ergonomics Society, 37(1), 5-19.

146 Sarter, N. B., Woods, D. D., \& Billings, C. E. (1997). Automation surprises. Handbook of Human Factors and Ergonomics, 2, 1926-1943.

147 Schad, D. J., Nuthmann, A., \& Engbert, R. (2012). Your mind wanders weakly, your mind wanders deeply: Objective measures reveal mindless reading at different levels. Cognition, 125(2), 179-194.

148 Schooler, J. W., Mrazek, M. D., Franklin, M. S., Baird, B., Mooneyham, B. W., Zedelius, C., et al. (2014). "The Middle Way" in Psychology of Learning and Motivation (Elsevier), 1-33.

149 Sebanz, N., Knoblich, G., \& Prinz, W. (2003). Representing others' actions: just like one's own?. Cognition, 88(3), B11B21.

150 Seli, P., Risko, E. F., \& Smilek, D. (2016). On the necessity of distinguishing between unintentional and intentional mind wandering. Psychological Science, 1,7 .

151 Shappell, S., Detwiler, C., Holcomb, K., Hackworth, C., Boquet, A., \& Wiegmann, D. A. (2007). Human error and commercial aviation accidents: an analysis using the human factors analysis and classification system. Human Factors: The Journal of the Human Factors and Ergonomics Society, 49(2), 227-242.

152 Sheridan, T. B., \& Verplank, W. L. (1978). Human and computer control of undersea teleoperators. MASSACHUSETTS INST OF TECH CAMBRIDGE MAN-MACHINE SYSTEMS LAB.

153 Simon, RJ., \& Small, M. (1969). « Processing auditory information: Interference from an irrelevant cue ». Journal of Applied Psychology 53: 433435.

154 Singh, I. L., Molloy, R., \& Parasuraman, R. (1993). Automation-induced“" complacency": Development of the complacency-potential rating scale. The International Journal of Aviation Psychology, 3(2), 111-122.

155 Smallwood, J. M., Baracaia, S. F., Lowe, M., \& Obonsawin, M. (2003). Task 
unrelated thought whilst encoding information. Consciousness and Cognition, 12(3), 452-484.

156 Smallwood, J., O'Connor, R. C., Sudbery, M. V., \& Obonsawin, M. (2007). Mindwandering and dysphoria. Cognition and Emotion, 21(4), 816-842.

157 Smallwood, J., Riby, L., Heim, D., \& Davies, J. B. (2006). Encoding during the attentional lapse: Accuracy of encoding during the semantic sustained attention to response task. Consciousness and Cognition, 15(1), 218-231.

158 Smallwood, J., \& Schooler, J. W. (2006). The restless mind. Psychological Bulletin, 132(6), 946-958.

159 Somon, B., Campagne, A., Delorme, A., \& Berberian, B. (2017). Performance Monitoring Applied to System Supervision. Frontiers in Human Neuroscience, 11 .

160 Stanton, N. A. (2016). Distributed situation awareness.

161 Stawarczyk, D., Majerus, S., Maquet, P., \& D'Argembeau, A. (2011). Neural Correlates of Ongoing Conscious Experience: Both Task-Unrelatedness and Stimulus-Independence Are Related to Default Network Activity. PLoS ONE, 6(2), e16997.

162 Strauch, B. (2002). Investigating Human Error: Incidents, Accidents, and Complex Systems. Ashgate.

163 Taleb, N. N. (2012). Antifragile: Things that gain from disorder (Vol. 3). Random House.

164 Taylor, S. F., Stern, E. R., \& Gehring, W. J. (2007). Neural Systems for Error Monitoring: Recent Findings and Theoretical Perspectives. The Neuroscientist, 13(2), 160-172.

165 Teasdale, J. D., Dritschel, B. H., Taylor, M. J., Proctor, L., Lloyd, C. A., NimmoSmith, I., \& Baddeley, A. D. (1995). Stimulus-independent thought depends on central executive resources. Memory \& Cognition, 23(5), 551-559.

166 Teichner, W. H. (1974). The detection of a simple visual signal as a function of time of watch. Human Factors, 16(4), 339352.
167 Thackray, R. I., \& Touchstone, R. M. (1989). A comparison of detection efficiency on an air traffic control monitoring task with and without computer aiding. US Departement of Transportation - Federal Aviation Administration.

168 Thomson, D. R., Seli, P., Besner, D., \& Smilek, D. (2014). On the link between mind wandering and task performance over time. Consciousness and Cognition, $27,14-26$.

169 Ullsperger, M., Danielmeier, C., \& Jocham, G. (2014). Neurophysiology of Performance Monitoring and Adaptive Behavior. Physiological Reviews, 94(1), 35-79.

170 Ullsperger, M., Nittono, H., \& von Cramon, D. Y. (2007). When goals are missed: Dealing with self-generated and externally induced failure. NeuroImage, 35(3), 1356-1364. https://doi.org/10.1016/j.neuroimage.2007 .01 .026

171 van Charante, E. M., Cook, R. I., Woods, D. D., Yue, L., \& Howie, M. B. (1993). Human-computer Interaction in Context: Physician Interaction with Automated Intravenous Controllers on the Heart. In Analysis, Design and Evaluation of ManMachine Systems 1992 (pp. 263-274). Elsevier.

172 van Schie, H. T., Mars, R. B., Coles, M. G. H., \& Bekkering, H. (2004). Modulation of activity in medial frontal and motor cortices during error observation. Nature Neuroscience, 7(5), 549-554.

173 Warm, J. S. (1984). An introduction to vigilance. Sustained Attention in Human Performance, 1-14.

174 Warm, J. S. (1993). Vigilance and target detection. Workload Transition: Implications for Individual and Team Performance, 2000.

175 Warm, J. S., Parasuraman, R., \& Matthews, G. (2008). Vigilance requires hard mental work and is stressful. Human Factors, 50(3), 433-441.

176 Warm, J. S., Parasuraman, R., \& Matthews, G. (2008). Vigilance Requires Hard Mental Work and Is Stressful. Human Factors: The Journal of the 
Human Factors and Ergonomics Society, 50(3), 433-441.

177 Wegner, D. M. (2002). The illusion of conscious will. MIT press.

178 Wickens, C. (1992). Engineering Psychology and Human Performance, chapter Motion sickness and perception: A reappraisal of the sensory conflict approach.

179 Wickens, C. D., \& Dixon, S. R. (2007). The benefits of imperfect diagnostic automation: A synthesis of the literature. Theoretical Issues in Ergonomics Science, 8(3), 201-212.

180 Wickens, C., Dixon, S., Goh, J., \& Hammer, B. (2005). Pilot dependence on imperfect diagnostic automation in simulated UAV flights: An attentional visual scanning analysis. DTIC Document. Retrieved from http://oai.dtic.mil/oai/oai?verb=getRecord \&metadataPrefix $=$ html\&identifier=ADA 4 46167

181 Wickens, C. D., \& Kessel, C. (1979). The effects of participatory mode and task workload on the detection of dynamic system failures. IEEE Transactions on Systems, Man, and Cybernetics, 9(1), 2434.

182 Wickens, C. D., \& Kessel, C. (1981). Failure detection in dynamic systems. In Human detection and diagnosis of system failures (pp. 155-169). Springer.

183 Wiener, E. L. (1989). Human factors of advanced technology (glass cockpit) transport aircraft.

184 Wiener, E. L., \& Curry, R. E. (1980). Flight-deck automation: promises and problems. Ergonomics, 23(10), 995-1011.

185 Wiener, E. L., \& Nagel, D. C. (1988). Human factors in aviation. Gulf Professional Publishing.

186 Willems, B., \& Truitt, T. R. (1999). Implications of reduced involvement in en route air traffic control. DTIC Document. Retrieved from http://oai.dtic.mil/oai/oai?verb=getRecord \&metadataPrefix $=\mathrm{html} \&$ identifier $=\mathrm{ADA} 3$ 69584

187 Wohlschläger, A., Engbert, K., \& Haggard, P. (2003). Intentionality as a constituting condition for the own self- and other selves. Consciousness and cognition, 12(4), 708-716.

188 Wohlschläger, A., Haggard, P., Gesierich, B., \& Prinz, W. (2003). The perceived onset time of self-and other-generated actions. Psychological Science, 14(6), 586-591.

189 Woods, D., \& Tinapple, D. (1999). W3: Watching human factors watch people at work. Presented at the Presidential address, presented at the 43rd Annual Meeting of the Human Factors and Ergonomics Society, Houston, TX.

190 Yanko, M. R., \& Spalek, T. M. (2014). Driving With the Wandering Mind: The Effect That Mind-Wandering Has on Driving Performance. Human Factors: The Journal of the Human Factors and Ergonomics Society, 56(2), 260-269.

$191 \mathrm{Yu}, \quad$ R., \& Zhou, X. (2006). Brain responses to outcomes of one's own and other's performance in a gambling task. Neuroreport, 17(16), 1747-1751.

192 Zimmermann, M., Bauer, S., Lutteken, N., Rothkirch, I. M., \& Bengler, K. J. (2014, May). Acting together by mutual control: Evaluation of a multimodal interaction concept for cooperative driving. In Collaboration Technologies and Systems (CTS), 2014 International Conference on (pp. 227-235). IEEE. 